\title{
Quality and women's satisfaction with maternal referral practices in sub-Saharan African low and lower-middle income countries: a systematic review
}

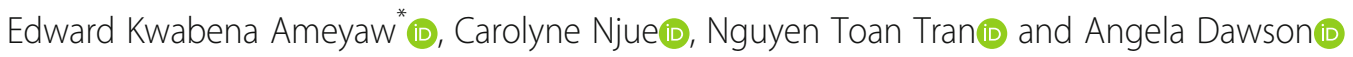

\begin{abstract}
Background: sub-Saharan African Low and Lower-Middle Income Countries (sSA LLMICs) have the highest burden of maternal and perinatal morbidity and mortality in the world. Timely and appropriate maternal referral to a suitable health facility is an indicator of effective health systems. In this systematic review we aimed to identify which referral practices are delivered according to accepted standards for pregnant women and newborns in sSA LLMICs by competent healthcare providers in line with the needs of pregnant women.

Methods: Six electronic databases were systematically searched for primary data studies (2009-2018) in English reporting on maternal referral practices and their effectiveness. We conducted a content analysis guided by a framework for assessing the quality of maternal referral. Quality referral was defined as: timely identification of signal functions, established guidelines or standards, adequate documentation, staff accompaniment and prompt care by competent healthcare providers in the receiving facility.

Results: Seventeen articles were included in the study. Most studies were quantitative $(n=11)$. Two studies reported that women were dissatisfied due to delays in referral processes that affected their health. Most articles (10) reported that women were not accompanied to higher levels of care, delays in referral processes, transport challenges and poor referral documentation. Some healthcare providers administered essential drugs such as misoprostol prior to referral.
\end{abstract}

Conclusions: Efforts to improve maternal health in LLMICs should aim to enhance maternity care providers' ability to identify conditions that demand referral. Low cost transport is needed to mitigate barriers of referral. To ensure quality maternal referral, district level health managers should be trained and equipped with the skills needed to monitor and evaluate referral documentation, including quality and efficiency of maternal referrals.

Trial registration: Systematic review registration: PROSPERO registration CRD42018114261.

Keywords: Quality maternal referral, Maternal referral practices, Sub-Saharan Africa, Signal functions, Referral standards, women's satisfaction, Referral guidelines

* Correspondence: edward.k.ameyaw@student.uts.edu.au

The Australian Centre for Public and Population Health Research, Faculty of

Health, University of Technology Sydney, Sydney, Australia

C C The Author(s). 2020 Open Access This article is licensed under a Creative Commons Attribution 4.0 International License, which permits use, sharing, adaptation, distribution and reproduction in any medium or format, as long as you give appropriate credit to the original author(s) and the source, provide a link to the Creative Commons licence, and indicate if changes were made. The images or other third party material in this article are included in the article's Creative Commons licence, unless indicated otherwise in a credit line to the material. If material is not included in the article's Creative Commons licence and your intended use is not permitted by statutory regulation or exceeds the permitted use, you will need to obtain permission directly from the copyright holder. To view a copy of this licence, visit http://creativecommons.org/licenses/by/4.0/. The Creative Commons Public Domain Dedication waiver (http://creativecommons.org/publicdomain/zero/1.0/) applies to the data made available in this article, unless otherwise stated in a credit line to the data. 


\section{Background}

Timely referral to an appropriate health facility to address maternity needs is a key indicator of a functional health system $[1,2]$. Efficient referral can result in a reduction of neonatal deaths with $18 \%$, stillbirths with $27 \%$ and maternal deaths with 50\% [3]. High quality referral is critical in low and lower-middle income countries (LLMICs) to prevent severe maternal morbidity that occurs in $8 \%$ of births in health facilities [4, 5]. In subSaharan Africa (sSA), obstructed labour, hypertensive disorders, unsafe abortion, sepsis and haemorrhage are the principal causes of maternal morbidity [6]. Multisectoral collaboration and well-coordinated levels of care, linking communities with essential maternal and newborn care is a necessary component of a high-quality referral system. Poor detection and treatment delays of complications is a major cause of maternal and perinatal mortality in LLMICs, particularly in sSA [7] where efforts are focused on improving standards of maternal and newborn referral $[8,9]$.

Maternity care that requires referral is usually due to complications that necessitate the use of life-saving services, or 'signal functions' as recommended by the World Health Organization (WHO) that cannot be provided by the referring facility [10]. Seven signal functions are recommended for basic emergency obstetric and neonatal care (BEmONC): administration of parenteral (1) antibiotics; (2) uterotonic drugs (e.g. oxytocin); (3) anticonvulsants (e.g. magnesium sulphate); (4) manual removal of retained placenta; (5) removal of other products of conception; (6) performing assisted vaginal birth and (7) neonatal resuscitation. Two additional services are recommended in the case of comprehensive EmONC (CEmONC) care: caesarean section and blood transfusion [10]. Any of these services may warrant referral.

According to WHO, all pregnant women should be correctly assessed upon presentation whether they can be attended to and if not immediately referred using a standard protocol. This should involve 'appropriate information exchange and feedback to relevant health care staff' [11]. Healthcare providers thus must communicate with the receiving facility in order for the woman to be managed efficiently. The receiving facility is also required to provide feedback on the outcome of the woman's status [11].

Some international standards and guidelines are difficult to implement in some settings in sSA due to limited human resources, funding, cultural factors, being irrelevant, geographic challenges or unattainable in the context [11-14]. As a result, some countries such as Ethiopia, Ghana and Kenya have developed countryspecific national level referral guidelines [15-17]. However, none of these is tailored towards maternal and newborn conditions.
Some systematic reviews on maternal and newborn referrals have been conducted in LLMICs, but these studies are based on evidence that is over a decade old [2, 18]. The review by Das, Gopalan excluded women who accessed the care [19]. Fikre [20] and Mahato et al. [21] limited their reviews to $\mathrm{BEmONC}$, narrowing the scope of maternal and newborn care [20, 21]. None of these recent studies examined the quality of maternal and newborn referral practices and women's satisfaction across SSA-LLMICs. Our research question was: "Which referral practices are delivered according to accepted standards for pregnant women and newborns in sSALLMICs by competent healthcare providers and in line with the need and wishes of women?"

\section{Methods}

Study design

This study was guided by the Population, Interventions, Comparators, Outcomes (PICO) framework [22]. Outcomes broadly fall under three key areas: quality of care (providers, referral system, information, medicines, and guidelines), satisfaction (women and family experience of referral) and effectiveness where available (health outcomes associated with referral). This systematic review was carried out following a priori protocol registered with PROSPERO [CRD42018114261].

A framework is a useful way to examine maternal and newborn referral, particularly in assessing elements of quality that are necessary for effective referral (S1). This framework has been adapted from the work of Hulton \& Matthews and seeks to assess the quality of maternal referral by linking some key distinct components of institutional healthcare provision [23]. These components comprise health facility management, medicines and psychosocial support. Newborn referral is subsumed under maternal referral by the framework. The framework has two main components: 1 . provision of maternal referral as provided by the health care system (supply) and 2. experience of referral as reported by women who utilise health facilities (demand). Most components under the supply section reflect elements of WHO's health system building blocks indicating that strengthening maternal and child health care and referrals could also improve the health system in general [24].

The Referral system implies how referrals are initiated and conducted, from $\mathrm{BEmONC}$ to $\mathrm{CEmONC}$ or from one CEmOC facility to another CEmOC level of care. Referral practice should be in line with internationally accepted standards and relevant to contextual characteristics [10, 11]. Human resources for health as indicated in the framework refer to the availability, competency and motivation of healthcare providers to recognise and refer cases to the appropriate facilities in a timely 


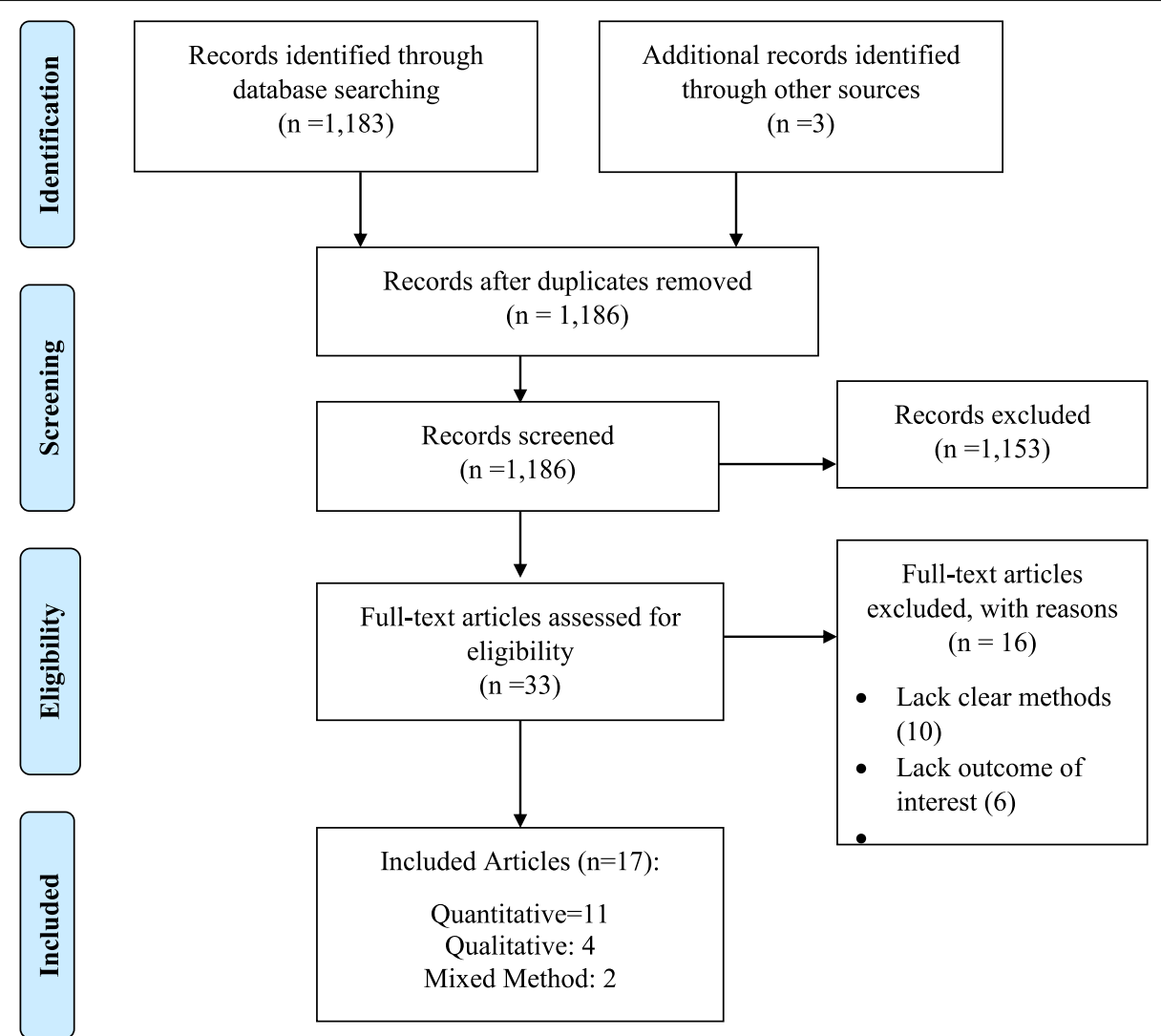

Fig. 1 PRISMA 2009 Flow Diagram

manner. It also encompasses satisfaction of women about healthcare providers' referral practices. Maternity information systems focus on the documentation of referred women or newborns including which data are collected, where and by whom. Medicines and equipment involve availability and appropriate use of essential lifesaving commodities for maternal and newborn health care such as the provision of a pre-referral loading dose of magnesium sulfate.

In terms of the demand side, Cognition focuses on whether women understood and were satisfied with the explanations given to them by healthcare providers. Respect, dignity and equity are concerned with whether women felt to have received respectful and equitable care. Women's views about the level of cleanliness, availability of medicines and equipment in health facilities as well as value for money are mirrored by satisfaction with facility, commodities and costs. Lastly, emotional support is related with women's perceptions of sensitive and responsive support by health care professionals.

\section{Data sources and search strategy}

We searched six databases: African Journals Online (AJOL), CINAHL (Ebsco), Embase (Ovid), MEDLINE (Ovid), Pubmed and Scopus for quantitative, qualitative or mixed- method articles. The search focused on studies published in English between 2009 and 2018 and conducted in sSALLMICs according to the World Bank definition [25]. The following search terms were used: "maternal referral" OR "obstetric referral" OR "referral practice" OR "obstetrics" OR "pregnancy complications" OR "maternal health services" OR "maternal and child health" OR "emergency obstetrics and newborn care (EmONC)" OR "comprehensive emergency obstetric and newborn care (CEmONC)" OR "referral guidelines" OR "referral standards" OR "referral effectiveness" OR "signal functions" OR "women satisfaction" OR "family's satisfaction" AND "sub-Saharan Africa" OR "Africa South of the Sahara" AND "low income countries" OR "lower-middle income countries". Relevant references from bibliographies were hand-searched in order to identify all relevant peer-reviewed articles. All searches were conducted from 22nd October to 29th November 2018.

Of the 1186 articles, 1153 were excluded after screening because of no outcomes of interest. A total of 33 were subjected to quality assessment after which 17 were included in our final analysis. Sixteen articles were excluded due to lack of clear methodology and limitations in the outcome of interest. The 17 articles included eleven quantitative, four qualitative and two mixedmethod studies (Fig. 1) [26]. 


\section{Quality assessment and data extraction}

The Critical Appraisal Skills Program (CASP) tool for qualitative research was used for assessing qualitative studies [27]. The McMaster Critical review form for quantitative studies was used [28].

\section{Data analysis}

Content analysis [29] was applied guided by the framework for assessing quality of maternity care (Error! Reference source not found.) [23]. Content analysis involves systematic and objective identification of key characteristics of texts in order to make inferences [29].

The findings section of the papers were then scrutinised to identify key outcomes of interest, data extracted and examined related to the main components of the framework. These findings comprised direct quotations and quantitative data relevant to the main supply and demand components of the framework. Consequently, all quotations in the results section are from the original papers.

\section{Results}

\section{Characteristics of included studies}

Seventeen articles were included in this review. Study aim, context, methodology and relevant findings are summarised in Table 1 . Most studies $(n=13)$ investigated the quality of referral from the healthcare providers' perspective either through interviews or audit of health facility records $[1,8,30-33,35-37,41-44]$. Two studies explored women's experiences of maternal and newborn referral [38, 39]. One study included both healthcare providers' and women's perspectives [40] whilst one South Sudanese study included perspectives of stakeholders from the local government sector, FaithBased Organisations (FBOs), non-governmental organisations (NGOs), and community religious leaders in addition to healthcare providers [34]. Common conditions that prompted referral included premature rupture of membranes, obstructed labour and postpartum complications, such as haemorrhage and fistula $[8,34,35$, $37,38,40,41]$. Outcomes in these studies are summarised in $\mathrm{S} 2$.

\section{Provision of maternity referral}

All 17 studies reported on various aspects of maternal and newborn referral and are presented under the subthemes as outlined by the supply side of the framework for assessing the quality of maternal referral.

\section{Referral system}

Two studies indicated use of standard maternal and newborn referral procedures, availability of standardised referral forms and health provider escorts [1, 36]. Awoonor-Williams \& Bailey [1] indicated that such procedures were accompanied by telephoning ahead to prompt the receiving hospital.

In that study in 16 facilities in Ghana, healthcare providers escorted all referred women and their newborns from health centres by ambulance to BEmOC and CEmOC facilities [1]. In two other studies in Ghana, health care providers rarely escorted women [31, 40]. Some referrals were unaccompanied because these were not emergencies [40]. Unaccompanied women sometimes arrived late [40].

Elmusharaf et al. [34] identified four referral pathways (Table 1) [34]. One woman narrated her zigzag referral:

Family members lifted the pregnant woman onto a donkey-driven cart and went to the village's medical assistant. When they arrived, her water broke. The medical assistant prescribed drugs and told them that she was in labour and that the midwife should deliver her straight away. He sent them back to the midwife for birth. After spending three hours with the midwife without progress, the pregnant woman was exhausted. The midwife advised them to go back to the medical assistant. They spent most of the night going back and forth between a midwife and a medical assistant until the midwife insisted on the medical assistant referring them to hospital (5JMD) [34].

In a study from Angola delays of up to $13.7 \mathrm{~h}$ were noted in the triage of referred women upon arrival in the receiving facility [42]. Referred women and their newborns were simply added to the queue with other patients. When healthcare providers were alerted about this issue, a meeting was held to identify referred women and prioritise them upon arrival. After this strategy was implemented, they spent an average of 9 min to meet a midwife and $71 \mathrm{~min}$ to be assessed by a doctor.

In Ghana, triage initiation for women in labour was found to vary by shift or timing of the day in one hospital [35]. Average waiting time in the morning was 35 min, $28 \mathrm{~min}$ in the evening and $55 \mathrm{~min}$ in the night. For a woman in the first stage of labour, it took an average of $35 \mathrm{~min}$ for triage to take place and $24 \mathrm{~min}$ after this for her to be admitted to the labour ward. Those in the second stage were evaluated within $30 \mathrm{~min}$ and moved to the labour ward within $10 \mathrm{~min}$ [35].

In Burundi, a $15 \%$ higher chance of neonatal deaths was observed for women who took $\geq 3 \mathrm{~h}$ to arrive in the next facility. Facilities had to call for an ambulance from another facility which delayed in some instances [43]. In the absence of ambulances, donkeydriven carts, tractors, pick-up trucks, public transport (taxis and lorries), motorised tricycles and motorbikes were used [31, 32, 36, 39, 40, 44]. 
Table 1 Summary of the 17 Articles

\begin{tabular}{llll}
\hline Reference & Country/Setting & Aim & Methods \\
\hline Abodunrin & Nigeria (urban and & To assess factors that & Descriptive quantitative \\
et al., 2010 & rural communities in & determine referral & survey: pre-tested semi- \\
[30] & llorin, the capital of & practices of Traditional & structured questionnaire \\
& Kwara State) & Birth Attendants (TBAs). & \\
& & &
\end{tabular}

\section{Sample}

162 Registered TBAs,

mean age $=46$ years,

$89.5 \%$ females, $71.6 \%$

married, 92\% Islam, 64.2\%

had at least primary

school education, $85.8 \%$

were part-time TBAs
Afari et al., 2014 [31]
Ghana (4 health posts, To describe whether 6 health centres and one district hospital in the Assin North Municipality) identified systemic challenges and the significance of local healthcare workers (HCW) structured interviews engagement in developing strategies to enhance emergency maternity referral related processes.
18 HCWs (1 doctor, 2 emergency room nurses, 3 medical assistants, 4 community health officers, 8 midwives)

\section{Findings}

- Identified timely and appropriate referrals among TBAs with more than one re-training (69.2\%) and TBAs who have ever been visited by a supervisor (45\%). Timely and appropriate referral was explained as referring women with high-risk pregnancies such as previous stillbirths, bleeding in previous or current pregnancies, multiple pregnancies, abnormal lie and not interfering with them. It also comprised immediate referral of women who had complications during labour management, such as bleeding during labour, prolonged labour, tiredness or loss of strength, seizures and retained placenta.

- Inappropriate referral comprised three conditions: delayed referral irrespective of the reason, wrong referral and non-referral. Delayed referral was defined as "not referring immediately any identified high-risk pregnancy and complicated labour."

- Wrong referrals were those to any place other than a modern health facility.

- A significant relationship was found between initial source of skills acquisition, re-training, supervision and prompt/appropriate referral of high-risk pregnancies.

- Young and unmarried TBAs with higher education had a higher tendency of appropriate and timely referral.

- Most TBAs who started through inheritance usually refer late or not.

- Gaps in existing referral protocols-signal function recognition for referral, stabilising patients, initiating referrals, transportation arrangement for referral:

"Sometimes they hire commercial vehicles and sometimes too they use the motorbike. If there is no commercial vehicle at the station, they will beg 
Table 1 Summary of the 17 Articles (Continued)

Reference Country/Setting Aim

someone to use their motorbike to convey them to the nearest health center or hospital, and then maybe somebody's private car. The person might sacrifice." CHO, Health Post - Few facilities adhered to national referral protocols. Poor referral

documentation and lack of communication between sending and receiving facilities were reported, although national referral protocols existed:

"Apart from that [one] guy (HCW) who calls, the others don't call so you'll be here and such a case comes in. And [...] with no... nobody accompanying... it's really a challenge. Because if you know [...] somebody is coming with eclampsia.. you know you're supposed to prepare first so that you receive [appropriately]." Emergency Nurse, District Hospital

"Somebody who is fitting (or convulsing), a pregnant woman who is fitting.. somebody (HCW) needs to accompany. But this is someone who is coming with relatives. They don't know they have to turn the head to the side, [or] the person can aspirate saliva and any other thing[s]." Nurse, District Hospital

- HCWs

recommendations:

standardising implementation of the referral protocol, enhancing transportation, ensuring dependable data reporting and management systems, actively engagement of community and offering continuous training for health staff.

Akaba \& Nigeria (from either a To determine maternal Ekele, 2018 primary, secondary, [32] emergency maternal tertiary or private health facility to University of Abuja Teaching Hospital, Gwagwalada)
All women requiring EmONC and referred from primary, secondary, tertiary or private health facility to University of Abuja Teaching Hospital, aged between 20 to 44 .
Prospective longitudinal study-November 2015 to March 2016, data from case-notes, cross-checked with referral documentation when available. referrals and reasons for these referrals.
- Nine cases (7.3\%) were

- Nine cases (7 ambulance.

- There was 8.9\% emergency referral fatality rate (11 maternal deaths/ 123 maternal referrals).

- 7/11 maternal deaths occurred among women referred from secondary health facilities.

- Poor emergency 
Table 1 Summary of the 17 Articles (Continued)

\begin{tabular}{|c|c|c|c|}
\hline Reference & Country/Setting & Aim & Methods \\
\hline $\begin{array}{l}\text { Awoonor- } \\
\text { Williams } \\
\text { et al., } 2015 \\
\text { [1] }\end{array}$ & $\begin{array}{l}\text { Ghana (Upper East } \\
\text { Region) }\end{array}$ & $\begin{array}{l}\text { Maternity referral audit to } \\
\text { strengthen the referral } \\
\text { system for pregnant } \\
\text { women and newborns in } \\
\text { northern Ghana. }\end{array}$ & $\begin{array}{l}\text { Quantitative, two-cycle } \\
\text { prospective audit in early } \\
2011 \text { and late } 2011 \text {; ques- } \\
\text { tionnaire, } 32 \text { facilities in } \\
\text { all- } 16 \text { facilities, } 12 \text { health } \\
\text { centres, } 3 \text { district and } 1 \text { re- } \\
\text { gional hospital }\end{array}$ \\
\hline
\end{tabular}

Sample their newborns (223 in each of the two cycles) centres, 3 district and 1 re ional hospital

Quantitative crosssectional survey questionnaire

et al., 2016 government facilities [33] providing materna health care, urban Dar es Salaam.

o investigate healthcare providers regarding prevention and management of postpartum haemorrhage (PPH).
Elmusharaf South Sudan (Renk et al., 2017 County, Upper Nile [34] State)
To ascertain patterns and contributory factors of pregnant women's pathways from the onset of labour or complications until arriving in suitable health facilities.
Qualitative, Critical Incident Technique (CIT), Stakeholder Interviews.
28 key informants ( 2 from local government, 4 from county health department, 14 healthcare providers, 2 NGO employees, 3 Faith-Based Organisation (FBO) employees, 3 community religious leaders).
$102 / 115$ (88 7\%) nurses with midwifery training, 9 (7.8\%) nurses without doctors/medical/ clinical officers from 10

dispensaries (60.9\%), 2 hospitals (18.3\%), 1 health $104 / 115$ (90.4\%) females, 71 (62.8\%) with more than 6-year experience.

\section{Findings}

maternity referrals and fetal outcomes were reported: 14 (11.5\%) fresh stillbirths and six (4.9\%) macerated stillbirths) due to late presentation.

- Observed enhanced referral facilitative mechanisms-increased use of ambulances/vehicles for referrals (48 to 63\%); higher usage of referral forms (66 to 77\%); alerting receiving facilities through phone calls (38 to 65\%); increment in feedback from receiving facilities (58 to $70 \%) ;$ all 6 women referred twice in the 2 nd cycle were accompanied by health staff.

- All 14 facilities had referred $42.6 \%$ of women within the past three months.

- Forty-nine (42.6\%) providers had referred at least one woman in the three months preceding the survey.

- $67.8 \%$ of 115 providers

indicated consultation and referral communication systems are in place. - $65.2 \%$ of 115 providers reported establishment of maternal referral transport system.

- Identified four referral pathways-late referral, zigzagging referral, multiple referrals and bypassing non-functioning facilities. - Women who directly went to appropriate health facilities and bypassed non-functioning facilities survived.

- Competencies of healthcare providers and functionality of the initial point of care determined the pathway to further care.

- Trained midwives were found to be competent but TBAs were not. 10-week prospective cohort time-sequence information at arrival and from records and log2012 to 11-11-2012. books period from 9 to 9 -
1082 women with pregnancy complications, 15-46 years, 0-8 parity, 24-49 weeks gestation and explore the timeliness with which women enter CEmOC.
- Long waiting time upon arriving in receiving facility-40 min on average. - The most distant referral facilities were $50 \mathrm{~km}$ from $\mathrm{RRH}$.

- Gaps were identified in how maternal vital signs and labour assessments 
Table 1 Summary of the 17 Articles (Continued)

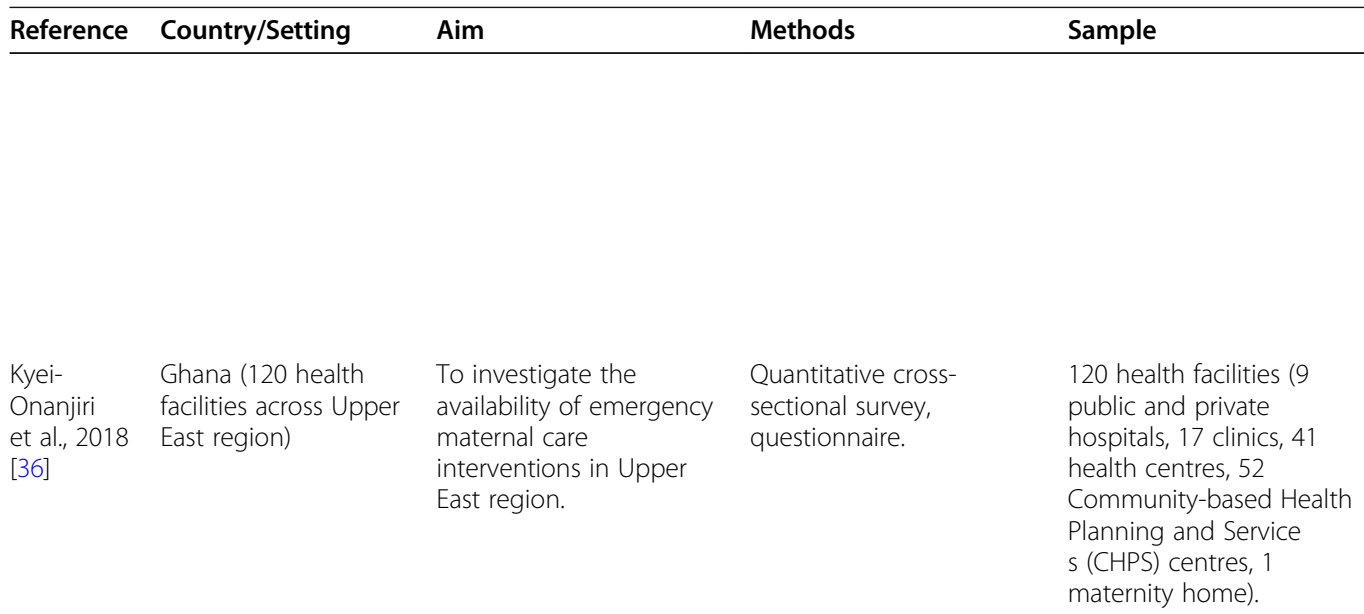

were recorded with 25 of

90 referrals found to be inappropriate. The most common reason for referral was for fetal-pelvic disproportion, however, fundal height was less than $40 \mathrm{~cm}$, which does not support this diagnosis. et al., 2018 East region)

[36]

Mirkuzie Ethiopia (10 public et al., 2016 health centres with [37] similar staff profile and providing EmONC, Addis Ababa)
To assess the proportion of maternal referrals resulting from premature rupture of membranes and investigate its correctness and management in Health centres.
Sequential explanatory mixed methods, routine retrospective data from birth and intrapartum referral logbooks and interviews, focused interview guide.
2820 women with maternal complications: 10 senior midwives

\section{Mselle \& Tanzania}

Kohi, 2016 (Comprehensive

[38]
Community Based Rehabilitation, a private, non-
To use women's narratives to demonstrate the challenges leading to failure in accessing adequate maternal care
Qualitative, narrative research, semi-structured

\section{interview guide}

th

16 women with obstetric fistula, aged between 19 and 43 years, $82 \%$ rural dwellers, all unemployed, $88 \%$ had no or primary
- 94\% health facilities were having standardised or printed referral forms for maternal referrals.

- $83 \%$ had a standard maternal referral

procedure.

- $64 \%$ had shortwave radio/telephone for referral communication. - $56 \%$ of facilities without shortwave radio/ telephone could not access one within minutes in instances where it is needed.

- Most facilities always had a trained health provider.

- 73\% had a midwife or doctor either on call or present at all times.

- All HC with high referral rates had many SBAs per caseload.

- $77.8 \%$ of the referred women had a spontaneous labour could have been wrongly referred because they were not in labour when they were referred.

- Some health centres observed women for about $8 \mathrm{~h}$ before referral initiation:

"... when we get mothers saying that their water has broken, after we evaluate them, they will be admitted to our health center and observed for about eight hours. If there is no spontaneous labour in eight hours we refer them to hospital after giving them a loading dose of Ampicillin... in the referral slip we write how long the mothers had been observed in our health center." (An informant from $\mathrm{HC}$ I).

- Delay in making referral decision was reported: "... it took 4 days at the village health facility, I could not give birth and 
Table 1 Summary of the 17 Articles (Continued)

\begin{tabular}{|c|c|c|c|c|c|}
\hline Reference & Country/Setting & Aim & Methods & Sample & Findings \\
\hline & $\begin{array}{l}\text { governmental organ- } \\
\text { isation in Dar es } \\
\text { Salaam) }\end{array}$ & in a timely manner & & education & $\begin{array}{l}\text { then I was referred to the } \\
\text { big hospital" (Divorced, } \\
\text { aged 29, Kibakwe, } \\
\text { Dodoma). } \\
\text { "...In the health facility, I } \\
\text { spend the night until } \\
\text { morning ... I had pains, } \\
\text { the day passed, I slept } \\
\text { again until morning again, } \\
\text { and it was when a decision } \\
\text { was made to transfer me } \\
\text { to another hospital. They } \\
\text { said it was because I had } \\
\text { urine retention. On the } \\
\text { third day is when I was } \\
\text { transported to a big } \\
\text { hospital" (Divorced, aged } \\
\text { 20, Mlandizi-Pwani). }\end{array}$ \\
\hline
\end{tabular}

$\begin{array}{ll}\text { Nuamah } & \text { Ghana (Antenatal } \\ \text { et al., 2016 } & \begin{array}{l}\text { clinics, Amansie West } \\ \text { [39] }\end{array} \\ & \begin{array}{l}\text { District in the Ashanti } \\ \text { region) }\end{array}\end{array}$

[39] region)
To evaluate the role of socio-economic factors, perception and transport availability in fulfilling maternity referrals
Quantitative crosssectional study, questionnaire
720 confirmed pregnant women from 5 subdistricts, $65.5 \%$ cohabitating, 28.8\% married, $49.6 \%$ JHS/Middle School, 17\% No formal education
- >90\% reported meeting staff in the receiving facility always.

- $76.6 \%$ disclosed that health staff in the receiving facility solved their problems.

- Most women were referred once and were not referred further.

- Commercial cars (88.2\%) are more often used for referral than ambulances (6.6\%). 46 aged women, $92 \%$ married, 44.6\% Unorthodox Christians, 35.6\% Orthodox Christians, $52.1 \%$ Junior High School, $12.8 \%$ no education, $76.2 \%$ traders, $43.6 \%$ parity 1, $29.7 \%$ parity 2
390 women attending ANC antenatal care clinic attendees and in-depth interviews with principal health care personnel, 17

- Out of 17 women referred in their current pregnancies, none of them was sent by and facility review checklist

Ambulance, ten had public transport whilst seven made their own transport arrangement. - Of the 17, fourteen got to the referral centre within $24 \mathrm{~h}$, two within $48 \mathrm{~h}$ and one woman got there after 10 days. - 15 had referral letters, but only 1 was accompanied by staff. - Only one hospital had information computerized for easy access.

- Referring health facilities hardly received feedback: "We don't receive any feedback from the hospitals. At least it would help us understand what we could have done better." (In-depth Interview, Medical Officer) - During maternity emergencies, they contact referral centres by mobile phone to find out if beds are available:

"There are hindrances between the two hospitals, 
Table 1 Summary of the 17 Articles (Continued)

\begin{tabular}{|c|c|c|}
\hline Reference & Country/Setting & Aim \\
\hline $\begin{array}{l}\text { Okafor } \\
\text { et al., } 2015 \\
\text { [8] }\end{array}$ & $\begin{array}{l}\text { Nigeria (Semino } \\
\text { Hospital and Maternity } \\
\text { (SHM), Enugu State) }\end{array}$ & $\begin{array}{l}\text { To audit childbirth } \\
\text { emergency referrals by } \\
\text { trained TBAs }\end{array}$ \\
\hline $\begin{array}{l}\text { Shimoda } \\
\text { et al., } 2015 \\
\text { [41] }\end{array}$ & $\begin{array}{l}\text { Tanzania (urban, one } \\
\text { regional referral } \\
\text { hospital and one } \\
\text { health centre in Dar es } \\
\text { Salaam city) }\end{array}$ & $\begin{array}{l}\text { To describe how } \\
\text { midwives monitor and } \\
\text { manage childbirth in } \\
\text { order to achieve early } \\
\text { consulting and timely } \\
\text { referral to obstetricians }\end{array}$ \\
\hline
\end{tabular}

Methods

Quantitative, retrospective, 205 women with case records retrieved and childbirth emergencies, data extracted with case $\quad 41.5 \%$ rural dwellers, record forms

Qualitative, semistructured interviews referral t

$58.5 \%$ urban dwellers, $90.2 \%$ married, $58.5 \%$ unemployed, $56.1 \%$ nullipara in the health centre during the day, 4 with
Strand et al., 2009 [42]
Angola (3 peripheral birth units-Cazenga,

Palanca and Sambizanga)
To assess the efficacy of the newly established network of peripheral birth units and their linkage to hospitals.
Tayler- Burundi (rural district, Smith et al., Kabezi)

2013 [43]
To describe Medecins sans Frontieres' communication and ambulance service, examine relationship between referral time and adverse outcome, explore effect of referral service on coverage of complications and caesarean sections.
Two-phase quantitative 157 referred women for survey, review of maternal records

Cross-sectional study retrospective analysis

st and 92 for 2 nd phase, years, $43 \%$ primiparae, 1 st phase referrals.
11 midwives, 12.5 average • Intrapartum year experience, 6 in the management and regional referral hospital, 5 monitoring/examination certificate, 4 with diploma, 2 with bachelor's degree, 1 with master's degree, 30-80 daily average births for their wards. 24.1 mean age, $36 \%<20$ $32 \% \geq 4$ previous births in

to arrive at referral decision consisted of 3 phases: 1) initial encountering, 2) monitoring, and 3) acting

that finally resulted in referral.

- Prompt referral upon identifying signal function beyond the facility's capacity:

"When she put in the catheter, we saw some blood starting to pass. That is the sign of obstructed labor. That's why I decided to refer immediately." (F)

- In instances where mother and fetus conditions are worsening, midwives decide earlier without taking time to confirm labour.

- 157 deaths (17.8\% case fatality rate) occurred among traced referrals in the first phase, no

maternal death in the second phase.

- Redacted proportion of referred women who were left without medical evaluation/treatment observed from the women's records (45\% in the first phase of the study to $27 \%$ in the second phase $(p=0.007)$.

1478 ambulance call-outs/ - Median referral time (time between call-out to the ambulance returning with the patient at (URGO) was $78 \mathrm{~min}$ - One maternal death occurred among referred women but it was not possible to evaluate the linkage between death and referral time. 
Table 1 Summary of the 17 Articles (Continued)

\begin{tabular}{|c|c|c|c|c|c|}
\hline Reference & Country/Setting & Aim & Methods & Sample & Findings \\
\hline & & & & & $\begin{array}{l}\text { - 3-h referral duration or } \\
\text { higher was associated } \\
\text { with increased risk of early } \\
\text { neonatal mortality-15\% as } \\
\text { compared with 9\% }\end{array}$ \\
\hline $\begin{array}{l}\text { Windsma } \\
\text { et al., } 2017 \\
\text { [44] }\end{array}$ & $\begin{array}{l}\text { Ethiopia ( } 20 \text { health } \\
\text { centres in the Eastern } \\
\text { Gurage Zone) }\end{array}$ & $\begin{array}{l}\text { To assess BEmONC, } \\
\text { knowledge of high-risk } \\
\text { pregnancies and referral } \\
\text { capacity in health centres }\end{array}$ & Cross-sectional survey & $\begin{array}{l}37 \text { healthcare providers } \\
\text { (18 heads of health } \\
\text { centres, } 14 \text { midwives, } 3 \\
\text { nurses, } 1 \text { health officer, } 1 \\
\text { other), } 45 \text { months average } \\
\text { of experience among } \\
\text { heads with } 27.5 \text { median } \\
\text { age, median age of } 24 \\
\text { years for others with } 24 \\
\text { months average } \\
\text { experience. }\end{array}$ & $\begin{array}{l}\text { - Most staff used their } \\
\text { own mobile phones for } \\
\text { referral correspondence- } \\
\text { only } 5 \text { facilities (26.3\%) } \\
\text { had a working landline } \\
\text { and } 1 \text { (5.3\%) facility had a } \\
\text { mobile phone. } \\
\text { - There were } 5 \text { ambulances } \\
\text { for the Eastern Gurage } \\
\text { Zone population: Two } \\
\text { stationed in health centres } \\
\text { and } 3 \text { in District Health } \\
\text { Offices. } \\
\text { - Distance to the referral } \\
\text { Butajira General Hospital } \\
\text { used by all health centres } \\
\text { was } 16.5 \text { km on average. } \\
\text { - There is a need to train } \\
\text { staff of the health centres } \\
\text { in the identification of } \\
\text { signal functions and } \\
\text { BEmONC. }\end{array}$ \\
\hline
\end{tabular}

Some health facilities were not equipped with telephones and some healthcare providers from primary health centres in southern Ethiopia had to use their personal phones to notify receiving facilities about referrals [44]. A communication system for facilitating referrals in 14 government health facilities in Tanzania was reported without details [33].

Referring health facilities are not always given feedback so that opportunities for improvement did not reach these $[31,40]$. High workload of health care workers was cited as the main reason why feedback was not given. A Medical Officer from Ghana reported:

"We don't receive any feedback from the hospitals. At least it would help us understand what we could have done better." (In-depth Interview, Medical Officer) [40].

However, in one study, feedback on referral was given verbally by the women or their families [1].

\section{International standards for the management of maternity emergencies}

Nwameme \& Phillips [40] indicated that more than $75 \%$ of staff from two of three facilities were trained how to use national referral guidelines. Two of the three studies reporting availability of national referral guidelines in Ghana indicated adherence in health facilities [1, 40]. Adherence includes documentation of referral indication, telephoning the referral facility ahead of time and arranging transportation, preferably by ambulance. In a survey of 120 health facilities in Ghana, $94 \%$ of the facilities had standard referral forms and $83 \%$ followed a standard referral procedure [36].

In Tanzania, guidelines for midwifery care were used in the studied hospital and health centre to manage intrapartum monitoring leading to emergency referrals of 11 women with prolonged labour [41]. Unlike WHO guidelines and recommendations, the national guidelines of Ghana do not mention that uterotonics should be applied to reduce haemorrhage $[11,16]$.

\section{Human resources for health}

A variety of providers were involved in maternity referrals, but few details were available regarding their experience and training $[1,30,31,33,36,39-41,44,45]$. Three papers reported that midwives and nurses had between two and 12.5 years of experience $[41,44]$ and doctors and nurses with midwifery training had at least 6 years [33].

In 14 government health facilities in Tanzania, 17\% of 115 health care providers could correctly diagnose postpartum haemorrhage (blood loss $\geq 500 \mathrm{ml}$, or blood loss of $500 \mathrm{ml}$ with shock symptoms) [33]. Almost all healthcare providers $(98.3 \%)$ knew that misoprostol can be used for post-partum haemorrhage (PPH), but only $62.6 \%$ was able to state the recommended dose $(600 \mu \mathrm{g})$ and $36.5 \%$ were able to prescribe it, because it was not 
always available [33]. No significant differences were found in the mean scores of PPH-related knowledge between providers who had $>6$ years of experience or less.

The $268 / 350$ (76.6\%) women who were referred to a higher level facility in Ghana reported that healthcare providers were competent enough to solve their problems [39]. In Kwara State in Nigeria, 128 (79.0\%) Traditional Birth Attendants (TBAs) indicated that they did not refer in a timely manner [30]. These were untrained TBAs who acquired their skills through self-initiation or inheritance. Nine of the twenty TBAs who had at least one supervisory visit by a qualified provider were able to conduct appropriate referral. In addition, nine out of the thirteen TBAs who had attended $>1$ training course, referred women with complications appropriately [30].

Okafor, Arinze-Onyia [8] also reported that trained TBAs in Nigeria delayed referral for women with signs of difficulty in childbirth for $>12 \mathrm{~h}$ [8]. A senior manager in a Reproductive Health and Midwifery Department in South Sudan complained about their competencies:

In the past, TBAs have arrived in Renk hospital with pregnant women with their babies partly delivered; parts of the foetus, such as the head, the arm or the leg, outside the woman's body and the rest of the body still inside. (Senior Manager) [34].

Poor skills of lower level doctors and midwives were reported in Ghana:

"Last time a pregnant woman came here .... And I was saying but there is a doctor at your place, so why did you rush here without a midwife accompanying you, and she said 'Auntie, I had been admitted there for a long time. And each time the doctor came, he said let's wait a bit more, and I was experiencing a lot of discomfort, and insisted that they discharge me, so they finally reluctantly discharged me.' And when she arrived here, true, it was twins. But one was IUFD (macerated) already. So she was able to get the first twin alive." (Midwife, District Hospital).

Health professionals noted the need for ongoing professional development. One midwife said:

"They (staff in the district hospital) need refresher courses... They should allow them to go to workshops so that they will see what is going on .... Me, I always learn from my junior nurses and midwives because I joined it [midwifery] about 10 years ago, and things are changing. Even the instrument [s] we are using [are] changing." (Midwife, Health Centre) [31].

\section{Maternity information systems}

Some health facilities in Ghana routinely used logbooks, care plans, referral letters and forms or slips correctly as required by the national referral guidelines [16]. Poor referral documentation was reported in Ghana where only six out of 11 sampled health facilities had referral registers and details concerning indications and treatment, while current status and treatment in the receiving facility were lacking and only one EmONC facility had a computerised referral information system [31, 40].

\section{Medicines and equipment}

In the seventeen studies, four included information concerning medicines and equipment such as misoprostol $[1,35,37,46]$. A decline in correct partograph use was reported in Ghana [1]. Audit in peripheral health facilities in Angola revealed poor quality of partographs without further detail [42]. In Tanzania, midwives correctly used catheters to enhance referral decision making.

\section{Experience of referral care}

No article provided insights into cognition and emotional support during referral. In Tanzania, some women in a primary health facility indicated that doctors were not readily available to check progress and refer to EmOC facilities, if necessary [38]. One woman narrated her story:

"When we got to the dispensary nurses told me to wait. At 8 pm labour pains became intense, I started pushing but the baby could not come out, and the doctor was not around. Next day I continued pushing the whole day again until at around $8 \mathrm{pm}$ when the doctor came ..." (Divorced, aged 33, Mbori Dodoma), [38].

Just over $10 \%(N=390)$ of women in three health facilities in Accra Ghana indicated that poor attitudes of nurses were a source constraint to referral [40]. In that study 180/390 women (46.2\%) complained about costs while three reported previous bad experiences as sources of dissatisfaction and constraints to referrals without further details [40].

\section{Socio-cultural factors affecting women's adherence to referral}

While the framework did not include socio-cultural factors, these were identified as having an effect on women's referral for care. In Ghana socio-cultural beliefs relating to fear of blood transfusion and fear of death in higher level facilities affected women's desire to travel to next level facilities [44]. In a CEmOC health facility in Ghana, 720 (57\%) women had to consult their husbands 
for permission to follow health professionals' advice [39]. For some women in rural Tanzania with obstetric fistula, the decision to travel to the next facility was made by their uncles, grandmothers, husbands and mothers-inlaw [38].

\section{Discussion}

Mere existence of referral guidelines does not imply their full application in maternal and newborn referrals in SSA LLMICs. Application of guidelines is hindered by heavy workloads, low competence of health care providers and non-availability of ambulances [13, 31, 34]. This requires greater policy attention and reaffirms lack of competent staff and essential medicines for managing maternity complications [45-48]. Strategies such as task sharing may be useful and involve upscaling of lower cadres of staff to conduct assessments to refer promptly or immediately receive women for treatment [49].

Few quality referrals were reported among lower-level midwives and nurses in clinics, health centres and medical centres [40, 41]. Training and supervision were, however, associated with higher quality referrals [32]. For TBAs, our findings reinforce the position of Sibley \&, Sipe that TBAs need to be trained to refer women [50]. Strong teamwork and collaboration between TBAs, lower and higher level health care providers could result in better outcomes [51]. Our findings corroborate the need to train district level managers in the skills needed to monitor the effectiveness of maternal and newborn referrals [52]. Consistent professional development is needed for all health workers to identify and manage complications and refer in a timely manner during all stages of labour [53].

Some women bypassed lower level facilities because they knew about potential delays in referral decisionmaking by lower level health care workers as noted in other studies [54, 55]. Other studies similarly showed that such delays as well as delays in triage initiation in referring facilities compromise the quality of referral $[9$, 56]. Regular monitoring and evaluation of referral processes especially at district level may be essential in improving referrals. Such activities can focus on specific indicators such as triage duration, referral decisionmaking competencies, referral outcomes and availability of means of transport for all maternity emergencies [52].

Using tools such as phone calls depending on feasibility and geographical context can be employed to facilitate referrals. Toll-free numbers for mobile phones and Geographic Information Systems (GIS) based transport have been used to coordinate and facilitate referral and transport arrangements [57-63].

Poor referral record keeping is consistent with other studies resulting from limited knowledge of health care providers or financial constraints $[31,64,65]$.
Mechanisms that encourage health care providers to have detailed documentation, in addition to userfriendly forms and provider training on the relevance of documentation could improve this.

The instrumental role of free or low cost, safe and reliable transport, preferably with ambulances, has been widely acknowledged [66-69]. Motorcycle ambulances could be used as relatively cheaper options [70]. Our findings corroborate the need to strengthen transport for maternal and newborn referral free of charge to women and their families [71]. An efficient, low cost transport system provides women with positive referral experiences [72]. The cost of transportation to the referred facility may dissuade women from adhering to referral advice [73]. Future maternal health policies should guarantee free timely referral and these could make use of pro-poor health insurance schemes, user-fee exemptions and vouchers $[74,75]$.

Limited decision-making capacity of women, fear of blood transfusion and fear to die in higher level facilities have been noted by similar studies in sSA where men, in-laws and elders decide whether women are allowed to travel [76-78]. In rural Uganda, women enduring maternity pain were considered brave since pregnancy was perceived as a test of endurance [79]. These women considered referral facilities as the last resort due to preferences for traditional birthing at home [79]. Active community engagement is essential in overcoming these socio-cultural barriers [80]. Evidence indicates that involving men or women's partners is beneficial because men can escort women if they understand why women are referred [81-83].

Poor performance may be a source of dissatisfaction, especially where shortages of skilled health professionals exist [47-49]. Lack of medical supplies and essential utilities such as electricity and clean water could also result in poor care experiences as reported in South Sudan [84]. Training adequate numbers of maternity care providers and ensuring an equitable distribution can mitigate the challenges confronting quality maternal and newborn referrals $[85,86]$.

No study in our review investigated women's experiences in relation with human-centred and dignified care. Women who feel to be respected, treated with equity and offered emotional support have better post-partum psychological outcomes [87]. WHO notes that about $10 \%$ of pregnant women and $13 \%$ of women just after birth encounter mental health issues globally [88]. These are even higher (15.6\% during pregnancy and $19.8 \%$ after birth) in sSA LLMICs. This prompts the need for maternity care providers to prioritise emotional wellbeing of women, especially after referral.

Quality referral was interpreted differently in the different studies. Some focused on the ability of healthcare 
providers to identify and initiate referral, having means of transport and detailed documentation of referrals. These fit well within our conceptual framework as indispensable elements in achieving high-quality maternity referrals [23]. Our findings imply the absence of a standard definition of quality referral, yet these key elements must characterise a maternity referral system that seeks to achieve desirable outcomes and positive maternal experiences. Monitoring and evaluation aimed at determining whether referrals reflect those features are needed to enhance referral $[11,67]$.

\section{Strengths and limitations}

Our study followed the PRISMA Statements for conducting systematic reviews. The study was underpinned by a framework that provides a balance between embracing quality referrals from the perspectives of both healthcare providers and women. The study was limited, however, to articles published in English in sSA LLMI Cs.

\section{Conclusion}

Referral guidelines are not always properly implemented due to human resource constraints, referral costs borne by women and their families, poor coordination between levels of care and limited availability of equipment, medicines and transport issues. Governments, planning agencies and healthcare administrators need to focus on more operationally-oriented guidelines to enable health facilities to facilitate maternal and newborn referral. There is a need for well-coordinated and strengthened teamwork and collaboration between PHC, BEmOC and $\mathrm{CEmOC}$ providers. Community education and interventions can encourage men to be involved in maternity care. Low cost transport is needed to mitigate barriers for referral. To ensure quality maternal and newborn referral, mechanisms should be instituted for health managers at district level to monitor and evaluate referral documentation, its quality and efficiency regularly.

\section{Supplementary information}

Supplementary information accompanies this paper at https://doi.org/10 1186/s12884-020-03339-3.

Additional file $1 \mathbf{S} \mathbf{1}$. Framework for assessing the quality of maternal referrals. Source: Adapted from Hulton, Matthews \& Stones, 2000.

Additional file $\mathbf{2}$ Table 2. Summary of findings

\section{Abbreviations}

BEmONC: Basic emergency obstetric and newborn care;

CEmONC: Comprehensive emergency obstetric and newborn care; EmOC: Emergency and obstetric care; EmONC: Emergency obstetric and newborn care; FBO: Faith-based organisation; GIS: Geographic information systems; NGOs: Non-governmental organisations; PRISMA: Preferred reporting items for systematic reviews and meta-analyses; sSA-LLMICs: Sub-Saharan
African low and lower middle income countries; TBA: Traditional birth attendant; WHO: World health organisation

\section{Acknowledgements}

We express our profound gratitude to the Faculty of Health, University of Technology Sydney, for funding this study.

\section{Authors' contributions}

EKA conceived the study, EKA and CN conducted the search and extracted the data. EKA and CN conducted the quality assessment. EKA, CN, AD and NTT compiled, designed the study, interpreted the data and revised the manuscript. All authors read and approved the final version.

\section{Funding}

This study was funded by the Faculty of Health, University of Technology Sydney, Australia.

Availability of data and materials

All analysed data are included in this article.

Ethics approval and consent to participate

Not applicable.

Consent for publication

Not applicable.

Competing interests

The authors declare that they have no competing interests.

Received: 8 August 2019 Accepted: 15 October 2020

Published online: 11 November 2020

\section{References}

1. Awoonor-Williams JK, Bailey PE, Yeji F, et al. Conducting an audit to improve the facilitation of emergency maternal and newborn referral in northern Ghana. Global Public Health. 2015;10(9):1118-33.

2. Hussein J, Kanguru L, Astin M, et al. The effectiveness of emergency obstetric referral interventions in developing country settings: a systematic review. PLoS Med. 2012;9(7):e1001264.

3. Pattinson R, Kerber K, Buchmann E, et al. Stillbirths: how can health systems deliver for mothers and babies? Lancet. 2011;377(9777):1610-23.

4. Tunçalp Ö, Hindin MJ, Souza J, et al. The prevalence of maternal near miss: a systematic review. BJOG. 2012;119(6):653-61.

5. Geller SE, Koch AR, Garland CE, et al. A global view of severe maternal morbidity: moving beyond maternal mortality. Reprod Health. 2018;15(1):98.

6. Tura AK, Trang TL, van den Akker T, et al. Applicability of the WHO maternal near miss tool in sub-Saharan Africa: a systematic review. BMC Pregnancy Childbirth. 2019:19(1):79.

7. Paxton A, Maine D, Freedman $L$, et al. The evidence for emergency obstetric care. Int J Gynecol Obstet. 2005;88(2):181-93.

8. Okafor I, Arinze-Onyia S, Ohayi S, et al. Audit of childbirth emergency referrals by trained traditional birth attendants in Enugu, southeast, Nigeria. Ann Med Health Sci Res. 2015:5(4):305-10.

9. Nyamtema AS, Mwakatundu N, Dominico S, et al. Enhancing maternal and perinatal health in under-served remote areas in sub-Saharan Africa: a Tanzanian model. PLoS One. 2016;11(3):e0151419.

10. WHO, UNFPA, UNICEF, et al. Monitoring emergency obstetric care: a handbook. Geneva, Switzerland: WHO Press; 2009.

11. WHO. Standards for improving quality of maternal and newborn care in health facilities. Geneva, Switzerland: World Health Organisation; 2016.

12. WHO. WHO Recommended Interventions for Improving Maternal and Newborn Health. Geneva, Switzerland: World Health Organization; 2009.

13. M'Rithaa DK, Fawcus S, Korpela M, et al. The expected and actual communication of health care workers during the management of intrapartum: An interpretive multiple case study. Afr J Prim Health Care Fam Med. 2015:7(1):1-8.

14. Maaløe N, Meguid T, Housseine N, Tersbøl BP, Nielsen KK, Bygbjerg IC, van Roosmalen J. Local adaption of intrapartum clinical guidelines, United Republic of Tanzania. Bull World Health Organ. 2019;97(5):365.

15. Federal Democratic Republic of Ethiopia. Guideline for implementation of a Patient Referral System. Ministry of Health; 2010. 
16. Ministry of Health. Ministry of Health referral policy and guidelines. Ghana, Accra: Ministry of Health; 2012.

17. Kenya Ministry of Health. Kenya Health Sector Referral Implementation Guidelines. Nairobi, Kenya: Division of Emergency and Disaster Risk Management, Ministry of Health; 2014.

18. Dogba M, Fournier P. Human resources and the quality of emergency obstetric care in developing countries: a systematic review of the literature. Hum Resour Health. 2009;7(1):7.

19. Das A, Gopalan SS, Chandramohan D. Effect of pay for performance to improve quality of maternal and child care in low- and middle-income countries: a systematic review. BMC Public Health. 2016;16(1):321.

20. Fikre R. Factors that can affect the quality of emergency obstetric care in the health center level in developing countries: a systematic review of the literature. Pyrex J Nurs Midwifery. 2016;2(2):7-11.

21. Mahato PK, Van Teijlingen E, Simkhada $P$, et al. Determinants of quality of care and access to basic emergency obstetric and neonatal care facilities and midwife-led facilities in low and middle-income countries: a systematic review. J Asian Midwives. 2018;4(2):25-61.

22. CRD. Systematic reviews CRD's guidance for undertaking reviews in health care. York: Centre for Reviews and Dissemination, University of York; 2009.

23. Hulton L, Matthews Z, Stones RW. A framework for the evaluation of quality of care in maternity services. Southampton: University of Southampton; 2000.

24. WHO. Monitoring the building blocks of health systems: a handbook of indicators and their measurement strategies. Geneva: World Health Organization; 2010.

25. The World Bank. World Bank Country and Lending Groups 2018 [Available from: https://datahelpdesk.worldbank.org/knowledgebase/articles/906519world-bank-country-and-lending-groups.

26. Moher D, Liberati A, Tetzlaff J, et al. Preferred reporting items for systematic reviews and meta-analyses: the PRISMA statement. PLOS Med. 2009;6(7): e1000097.

27. CASP. CASP Qualitative Checklist 2018 [cited 2019 11/03]. Available from: http://www.casp-uk.net.

28. Law M, Stewart D, Pollock N, et al. Critical Review Form-Quantitative Studies. Canada: McMaster University; 1998.

29. Haggarty L. What is content analysis? Med Teach. 1996;18(2):99-101.

30. Abodunrin O, Akande T, Musa I, et al. Determinants of referral practices of clients by traditional birth attendants in Ilorin, Nigeria. Afr J Reprod Health 2010;14(2):77-84.

31. Afari $H$, Hirschhorn LR, Michaelis A, et al. Quality improvement in emergency obstetric referrals: qualitative study of provider perspectives in Assin North District, Ghana. BMJ Open. 2014;4(5):e005052.

32. Akaba GO, Ekele BA. Maternal and fetal outcomes of emergency obstetric referrals to a Nigerian teaching hospital. Trop Dr. 2018;48(2):132-5.

33. Carnahan LR, Geller SE, Leshabari S, et al. Healthcare providers' knowledge and practices associated with postpartum haemorrhage during facility delivery in Dar Es Salaam, Tanzania. Int J Gynecol Obstet. 2016;135(3):268-71.

34. Elmusharaf K, Byrne E, AbuAgla A, et al. Patterns and determinants of pathways to reach comprehensive emergency obstetric and neonatal care (CEmONC) in South Sudan: qualitative diagrammatic pathway analysis. BMC Pregnancy Childbirth. 2017;17(1):278: 1-15.

35. Goodman DM, Srofenyoh EK, Olufolabi AJ, et al. The third delay: understanding waiting time for obstetric referrals at a large regional hospital in Ghana. BMC Pregnancy Childbirth. 2017;17(1):216.

36. Kyei-Onanjiri M, Carolan-Olah M, Awoonor-Williams JK, et al. Review of emergency obstetric care interventions in health facilities in the Upper East Region of Ghana: a questionnaire survey. BMC Health Serv Res. 2018;18(1).

37. Mirkuzie AH, Sisay MM, Bedane MM. High proportions of obstetric referrals in Addis Ababa: the case of term premature rupture of membranes. BMC Res Notes. 2016:9:40.

38. Mselle LT, Kohi TW. Healthcare access and quality of birth care: narratives of women living with obstetric fistula in rural Tanzania. Reprod Health. 2016; 13(1):87.

39. Nuamah GB, Agyei-Baffour P, Akohene KM, et al. Incentives to yield to obstetric referrals in deprived areas of Amansie west district in the Ashanti region, Ghana. Int J Equity Health. 2016;15(1):117.

40. Nwameme AU, Phillips JF, Adongo PB. Compliance with emergency obstetric care referrals among pregnant women in an urban informal settlement of Accra, Ghana. Matern Child Health J. 2014;18(6):1403-12.
41. Shimoda K, Leshabari S, Horiuchi S, et al. Midwives' intrapartum monitoring process and management resulting in emergency referrals in Tanzania: a qualitative study. BMC Pregnancy Childbirth. 2015;15:248.

42. Strand RT, de Campos PA, Paulsson G, et al. Audit of referral of obstetric emergencies in Angola: a tool for assessing quality of care. Afr J Reprod Health. 2009;13(2):75-86.

43. Tayler-Smith $\mathrm{K}$, Zachariah $\mathrm{R}$, Manzi $\mathrm{M}$, et al. An ambulance referral network improves access to emergency obstetric and neonatal care in a district of rural Burundi with high maternal mortality. Tropical Med Int Health. 2013;18(8):993-1001.

44. Windsma M, Vermeiden T, Braat F, et al. Emergency obstetric care provision in southern Ethiopia: a facility-based survey. BMJ Open. 2017;7(11):e018459.

45. Combs Thorsen V, Sundby J, Malata A. Piecing together the maternal death puzzle through narratives: the three delays model revisited. PloS One. 2012; 7(12):e52090-e.

46. Ueno E, Adegoke AA, Masenga G, et al. Skilled birth attendants in Tanzania: a descriptive study of cadres and emergency obstetric care signal functions performed. Matern Child Health J. 2015;19(1):155-69.

47. Geleto A, Chojenta C, Musa A, et al. Barriers to access and utilization of emergency obstetric care at health facilities in sub-Saharan Africa: a systematic review of literature. Syst Rev. 2018;7(1):183.

48. Pembe AB, Paulo C, D'mello BS, et al. Maternal mortality at Muhimbili National Hospital in Dar-es-salaam, Tanzania in the year 2011. BMC Pregnancy Childbirth. 2014;14(1):320.

49. Dawson AJ, Buchan J, Duffield C, et al. Task shifting and sharing in maternal and reproductive health in low-income countries: a narrative synthesis of current evidence. Health Policy Plann. 2013;29(3):396-408.

50. Sibley L, Sipe TA, Koblinsky M. Does traditional birth attendant training improve referral of women with obstetric complications: a review of the evidence. Soc Sci Med. 2004;59(8):1757-68.

51. Keri L, Kaye D, Sibylle K. Referral practices and perceived barriers to timely obstetric care among Ugandan traditional birth attendants (TBA). Afr Health Sci. 2010;10(1):75-81.

52. Murray SF, Davies S, Phiri RK, et al. Tools for monitoring the effectiveness of district maternity referral systems. Health Policy Plan. 2001;16(4):353-61.

53. Ameh CA, van den Broek N. Making it happen: training health-care providers in emergency obstetric and newborn care. Best Pract Res Clin Obstet Gynaecol. 2015;29(8):1077-91.

54. Kiruja J, Osman F, Egal JA, et al. Maternal near-miss and death incidencesfrequencies, causes and the referral chain in Somaliland: a pilot study using the WHO near-miss approach. Sex Reprod Healthc. 2017;12:30-6.

55. Singh S, Doyle P, Campbell OM et al. Referrals between public sector health institutions for women with obstetric high risk, complications, or emergencies in india - a systematic review. PloS One. 2016;11(8):e0159793-e.

56. Mbachu II, Ezeama C, Osuagwu K, et al. A cross sectional study of maternal near miss and mortality at a rural tertiary Centre in southern Nigeria. BMC Pregnancy Childbirth. 2017;17(1):251.

57. Frimpong E, Oduro-Mensah E, Vanotoo L, et al. An exploratory case study of the organizational functioning of a decision-making and referral support call center for frontline providers of maternal and new born care in the Greater Accra region of Ghana. Int J Health Plann Manag. 2018;33(4):e1112-e23.

58. Gitaka J, Natecho A, Mwambeo HM, et al. Evaluating quality neonatal care, call Centre service, tele-health and community engagement in reducing newborn morbidity and mortality in Bungoma county, Kenya. BMC Health Serv Res. 2018;18(1):493.

59. Chowdhury Al, Haider R, Abdullah AYM, et al. Using geospatial techniques to develop an emergency referral transport system for suspected sepsis patients in Bangladesh. PLoS One. 2018;13(1):e0191054.

60. Harahap NC, Handayani PW, Hidayanto A. Barriers and technologies of maternal and neonatal referral system in developing countries: a narrative review. Inform Med Unlocked. 2019;15:100184.

61. Battle JD, Farrow L, Tibaijuka J, et al. mHealth for safer deliveries: a mixed methods evaluation of the effect of an integrated mobile health intervention on maternal care utilization. Healthc (Amst). 2015;3(4):180-4.

62. Martinez B, Ixen EC, Hall-Clifford R, et al. mHealth intervention to improve the continuum of maternal and perinatal care in rural Guatemala: a pragmatic, randomized controlled feasibility trial. Reprod Health. 2018;15(1):120.

63. Ojo Al. mHealth interventions in South Africa: a review. SAGE Open. 2018; 8(1):2158244018767223

64. Umar AS, Kabamba L. Maternal mortality in the Main referral Hospital in Angola, 2010-2014: understanding the context for maternal deaths amidst poor documentation. Int J MCH AIDS. 2016;5(1):61-71. 
65. Odekunle FF, Odekunle RO, Shankar S. Why sub-Saharan Africa lags in electronic health record adoption and possible strategies to increase its adoption in this region. Int J Health Sci. 2017;11(4):59-64.

66. Giovine A, Ostrowski C. Improving transportation and referral for maternal health: knowledge gaps \& recommendations. A technical report for the Woodrow Wilson International Center for Scholars; 2010.

67. Murray SF, Pearson S. Maternity referral systems in developing countries: current knowledge and future research needs. Soc Sci Med. 2006;62(9): 2205-15.

68. Bailey PE, Keyes EB, Parker C, et al. Using a GIS to model interventions to strengthen the emergency referral system for maternal and newborn health in Ethiopia. Int J Gynecol Obstet. 2011;115(3):300-9.

69. Surridge $M$, Green $C$, Kaluba $D$ et al. Filling a gap in the referral system: linking communities to quality maternal health care via an emergency transport system in six districts of Zambia. Report Prepared for Mobilising Access to Maternal Health Services in Zambia 2014.

70. Hofman JJ, Dzimadzi C, Lungu K, et al. Motorcycle ambulances for referral of obstetric emergencies in rural Malawi: do they reduce delay and what do they cost? Int J Gynecol Obstet Gynecol. 2008;102(2):191-7.

71. Ngoma T, Asiimwe AR, Mukasa J, et al. Addressing the second delay in saving mothers, giving life districts in Uganda and Zambia: reaching appropriate maternal care in a timely manner. Glob Health Sci Pract. 2019; 7(Supplement 1):S68-84.

72. Pembe $A B$, Urassa DP, Darj $E$, et al. Qualitative study on maternal referrals in rural Tanzania: decision making and acceptance of referral advice. Afr J Reprod Health. 2008;12(2):120-31.

73. Pembe AB, Carlstedt A, Urassa DP, et al. Effectiveness of maternal referral system in a rural setting: a case study from Rufiji district, Tanzania. BMC Health Serv Res. 2010;10:326.

74. Hatt LE, Makinen M, Madhavan S, et al. Effects of user fee exemptions on the provision and use of maternal health services: a review of literature. J Health Popul Nutr. 2013;31(4 Suppl 2):S67.

75. Dennis ML, Abuya T, Campbell OMR, et al. Evaluating the impact of a maternal health voucher programme on service use before and after the introduction of free maternity services in Kenya: a quasi-experimental study. BMJ Glob Health. 2018;3(2):e000726.

76. Yarney L. Does knowledge on socio-cultural factors associated with maternal mortality affect maternal health decisions? A cross-sectional study of the Greater Accra region of Ghana. BMC Pregnancy Childbirth. 2019;19(1): 47.

77. Dapaah JM, Nachinaab JO. Sociocultural determinants of the utilization of maternal health Care Services in the Tallensi District in the upper east region of Ghana. Adv Public Health. 2019;2019:11.

78. Pembe $A B$, Mbekenga $C K$, Olsson $P$, et al. Why do women not adhere to advice on maternal referral in rural Tanzania? Narratives of women and their family members. Glob Health Action. 2017;10(1):1364888.

79. Kyomuhendo GB. Low use of rural maternity Services in Uganda: impact of Women's status, traditional beliefs and limited resources. Reprod Health Matters. 2003;11(21):16-26.

80. WHO, Enfants du Monde, PAHO. Working with individuals, families and communities to improve maternal and newborn health: a toolkit forimplementation. Geneva: WHO; 2017 [cited 2019 07/06]. Available from: https://www.who.int/maternal_child_adolescent/documents/communityengagement-mnh-toolkit/en/.

81. August F, Pembe AB, Mpembeni $R$, et al. Community health workers can improve male involvement in maternal health: evidence from rural Tanzania. Glob Health Action. 2016;9(1):30064.

82. Tokhi M, Comrie-Thomson L, Davis J, et al. Involving men to improve maternal and newborn health: a systematic review of the effectiveness of interventions. PLoS One. 2018;13(1):e0191620.

83. Elazan SJ, Higgins-Steele AE, Fotso JC, et al. Reproductive, maternal, newborn, and child health in the community: task-sharing between male and female health workers in an Indian rural context. Indian J Community Med. 2016;41(1):34.

84. Mugo NS, Dibley MJ, Damundu EY, et al. Barriers faced by the health workers to deliver maternal care services and their perceptions of the factors preventing their clients from receiving the services: a qualitative study in South Sudan. Matern Child Health J. 2018;22(11):1598-606.

85. Devkota HR, Murray E, Kett M, et al. Are maternal healthcare services accessible to vulnerable group? A study among women with disabilities in rural Nepal. PLoS One. 2018;13(7):e0200370.
86. Miteniece E, Pavlova M, Shengelia L, et al. Barriers to accessing adequate maternal care in Georgia: a qualitative study. BMC Health Serv Res. 2018; 18(1):631.

87. Nilsson $L$, Thorsell $T$, Hertfelt WE, et al. Factors influencing positive birth experiences of first-time mothers. Nurs Res Pract. 2013;2013:349124.

88. WHO. Maternal mental health. Geneva: WHO; 2019. [cited 2019 22/05]. Available from: https://www.who.int/mental_health/maternalchild/maternal_ mental_health/en/.

\section{Publisher's Note}

Springer Nature remains neutral with regard to jurisdictional claims in published maps and institutional affiliations.

\section{Ready to submit your research? Choose BMC and benefit from:}

- fast, convenient online submission

- thorough peer review by experienced researchers in your field

- rapid publication on acceptance

- support for research data, including large and complex data types

- gold Open Access which fosters wider collaboration and increased citations

- maximum visibility for your research: over $100 \mathrm{M}$ website views per year

At BMC, research is always in progress.

Learn more biomedcentral.com/submissions 